\title{
Spontaneous Fractures or Physical Abuse?
}

\author{
Gholam Hossein Kazemian, ${ }^{1}$ Alireza Manafi Rasi, ${ }^{2}$ Farzad Amoozadeh Omrani, ${ }^{2,}$ and A Yamrali ${ }^{3}$ \\ ${ }^{1}$ Associate Professor of Orthopedi, Orthopedic Department, Shahid Beheshti University of Medical Sciences, Imam Hussein Hospital, Tehran, Iran \\ ${ }^{2}$ Assistant Professor of Orthopedi, Orthopedic Department, Shahid Beheshti University of Medical Sciences, Imam Hussein Hospital, Tehran, Iran \\ ${ }^{3}$ Senior Resident of Orthopedi, Shahid Beheshti University of Medical Sciences, Imam Hussein Hospital, Tehran, Iran \\ "Corresponding author: Farzad Amoozadeh Omrani, Assistant Professor of Orthopedi, Orthopedic Department, Shahid Beheshti University of Medical Sciences, Imam Hussein \\ Hospital, Tehran, Iran. E-mail: farzad_amuzadeh@yahoo.com
}

Received 2016 August 06; Revised 2016 August 27; Accepted 2016 September 20.

\begin{abstract}
Spontaneous fractures occur in patients with Paget disease, Multiple myelomas, and osseous metastasis. Furthermore, spontaneous fractures may be the result of physiological pressure and stress on bones with reduced elastic tenacity. In this report, we have introduced an elderly patient with multiple significant fractures without any history of a major trauma. In the discussion, we have considered important issues around the topic.
\end{abstract}

Keywords: Spontaneous Fracture, Elderly, Physical Abuse

\section{Introduction}

Spontaneous fractures occur in patients with paget disease, multiple myelomas, and osseous metastasis. Furthermore, spontaneous fractures may be the result of physiological pressure and stress on bones with reduced elastic tenacity. This kind of fractures, also called bone insufficiency Fractures, are seen in old people suffering from osteoporosis or in those who are under radiotherapy or corticosteroid therapy $(1,2)$. Among this kind of fractures, Vertebra Collapse and Hip Bone Fractures have been studied more (3-6). But, this kind of fractures are less studied in long bones $(7,8)$.

In more cases, this kind of fractures are suspicious and bring to mind to be from physical abuse. In this study, we introduce and review Spontaneous long bone fractures in an elderly who does not have any previous history of metastatic cancer, paget disease, multiple myelomas, corticosteroid use, or radiotherapy. The only risk factor was osteoporosis which was due to immobilization. Also, there was no history of clear trauma. In reality, the significance of reviewing the Spontaneous fractures happening without any external force in the bedridden patients is not just in the clinical aspect but also in legal medicine.

Observing this kind of fractures in elderly care centers can be suspicious for the families, because these centers do not care or the patients may be subjected to physical abuse in these centers.

\section{Case Presentation}

An old woman at the age of 88 with a history of CVA 5 years before the time of the study, right hemiplegia, is- chemic heart disease (IHD), hyperlipidemia, hypertension, hypothyroidism, and the chief complaint of a reduction in her range of motion in right and left hands referred to the orthopedic emergency section at Imam Hossein hospital in Tehran.

When she came to the hospital, she lay on the bed, incapable of weight bearing and did not have good cooperation with the examiner. Apparently, there was not any other skeletal complaint by her and her husband did not mention anything more. There was no history of clear trauma told by her husband. He explained that the patient was always displaced carefully just in order to prevent bedsore and for the purpose of necessary cleansing and feeding. There was no history of falling from a height or bed, while the only person that always took care of her, as he said, was her husband. Also, the patient had undergone an operation because of bilateral femoral neck fractures approximately 5 years before the time of the study.

This patient had no history of Spontaneous fractures caused by Paget, Multiple myelomas, Metastatic cancers, corticosteroid use, or radiotherapy. The significant point of history was the absence of major trauma signs and that her husband stressed that the displacement of the patient was always accomplished gently with care. As there was no signs of abrasion, ecchymosis or other signs of head, chest, and abdominal trauma, and her husband was the only one who took care of her and he was the only source of history, there was doubt that there may have been a pathology of a physical abuse. Unfortunately, because of the low level of consciousness, the patient did not have enough cooperation in the range of motion examination in upper and lower limbs. She had tenderness in touching the left arm and shoulder. There was clear deformity presented in the 
distal of the left arm, the proximal and distal of the right arm and, also, in the first and the fifth finger of the left hand. She did not have cooperation in the nervous system examination of the upper and lower limbs.

Limbs' pulse examination was normal and there was no obvious deformity or tenderness in the other joints and long bones.

After the physical examination, radiography showed evidences of old fractures in the proximal and distal of the right humorous, distal of left humorous, and also signs of old fractures were seen in the proximal of the right radius, mid shift of right ulna, proximal and mid shift of left radius, first metacarpal of left hand and bilateral femoral neck that had been operated previously.

\section{Discussion}

Spontaneous fractures are fractures that happen without specific factors or in the absence of severity of trauma usually necessary to fracture a bone (9). Fractures caused by bone inadequacy or minor trauma are, also, called by this name (10). These kinds of fractures happen in elderly patients especially those with functional deficiency $(11,12)$. Although, vertebral bone fractures or hip bone fractures were frequently reported in elderly care centers $(12,13)$, few reports about long bone fractures of the elderly in Bedridden satates are present.

Spontaneous fractures of long bones (humorous, femur, tibia, fibula, and ulnar) are frequently caused by direct force or momentum force used for the displacement of the patient to prevent bedsore. Two important factors reducing the mass and the quality of bone because of immobility are chronic disease and malnutrition $(10,14)$. Increasing momentum force is because of passive displacement. Also, decreasing bone density from pelegic side compared to the other side with more speed was reported (15).

Another reason of a broken bone is joint contracture. Frequently, joint contracture is more observed in the pelagic side. Actually, joint contracture is due to fixing the limb and it works like a backrest for a momentum force introduced by patient displacement, this conduce to Spontaneous fracture of the bones exposed, and the external forces caused by changing the patients' position to make them stand or clean and change their clothes cause fractures of the long bones.

On the other hand, physical abuse in the old patients, especially in those suffering from multiple morbidity and whom are bedridden, is more probable. Most of them did not have efficient mechanisms for protecting themselves while they mostly lived in the elderly care centers where they might be abused or hurt by the staff. On the other hand, because of cognitive issues in such patients, most of them cannot express a perfect history that shows a pathogenic mechanism.

In this case, among lots of fractures that almost happened in long bones, two of them happened in the proximal and distal of the right humorous (hemiplegic side), that according to the patient's history and the bone fractures observed, physical abuse is possible (a diagnosis that may have a great value in the legal medicine). Also, spontaneous fractures of long bones, beside the above mechanism, indicates more possible diagnosis.

Kane and Goodman gave the first report about spontaneous fractures of old adults in the elderly care centers with no clear trauma (16). All the patients in their study had not been able to stand or endure their body weight for two years, except for osteoporosis; no risk factors like cancer or paget disease were present. More fractures were from hip or upper and lower long bones. In this study, in two cases, the patients had a good status; they clearly declared that there was no history of physical abuse.

In another study conducted by Martin-Hyundai on 3 025 elderly patients for 20 months in elderly care centers, Spontaneous fractures were about 1\% (14). Most of the fractures were in hip, shaft of femur, tibia, fibula, and humorous.

In another epidemilogic study, in elderly care centers, spontaneous fractures were $0.8 \%$ in one year (10). In this study, most fractures were in hip, in those with less movement in bedridden states.

Wong et al.'s study reported 30 Spontaneous fractures. Female gender, bedridden state, nutrition tube, dementia, joint contractor, and hemiplegia of the same side were introduced as risk factors (17).

These studies and the present report can explain that spontaneous fractures happen in old patients who are bedridden or have significant decrease in motion, and it can be caused by other people who do the daily activities for them; although, the subject of physical torture should always be kept in mind.

The diagnosis of Spontaneous fractures in this group of patients can help legal medicine. Also, this subject can reveal the importance of the education of the nurses of elderly care centers or the patient's relatives. 


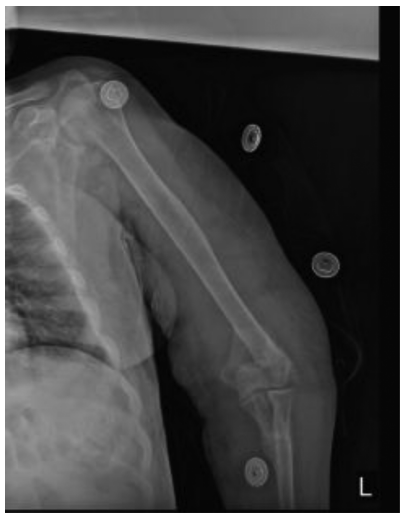

Figure 1. Figure 1

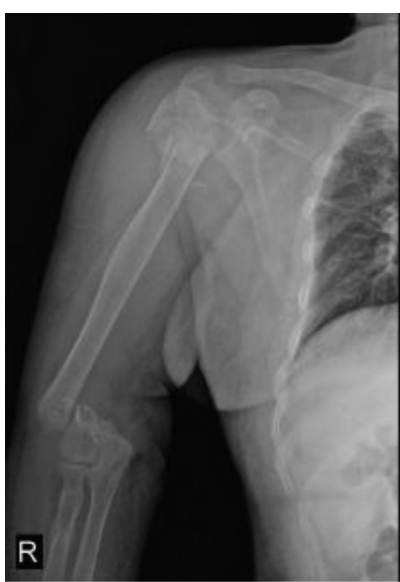

Figure 2. Figure 2

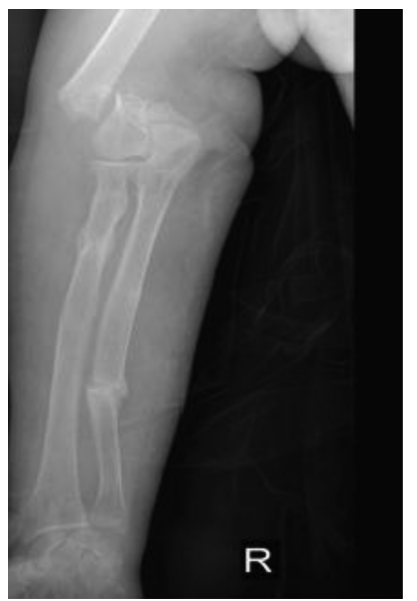

Figure 3. Figure 3

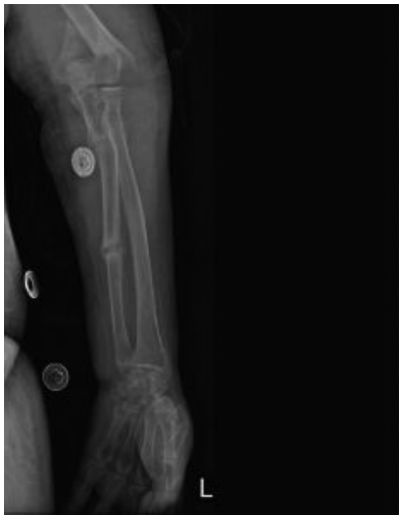

Figure 4. Old Fracture in Head and the Mid Shaft of the Left Ulna, Radius Head and the Mid Shaft of the Right Ulna

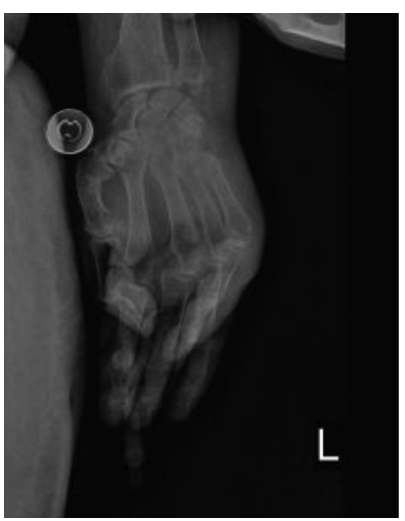

Figure 5. The Breaking of the First Metacarpal of the Left Hand and the Distal Humorous of the Right Hand

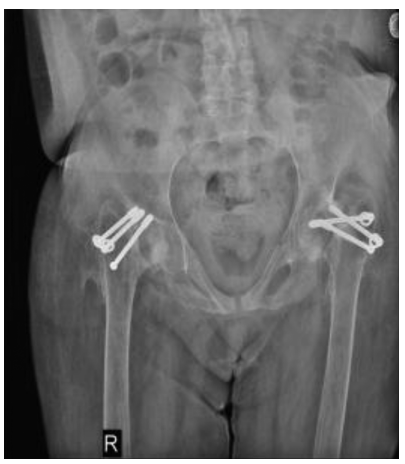

Figure 6. Old Operation of the Bilateral Femoral Neck Fracture

\section{References}

1. Daffner RH, Pavlov H. Stress fractures: current concepts. AJR Am J Roentgenol. 1992;159(2):245-52. doi: 10.2214/ajr.159.2.1632335. 
[PubMed: 1632335].

2. Soubrier M, Dubost JJ, Micheau V, Sauvezie B, Ristori JM, Bussièe JL. Insufficiency fracture. A survey of 60 cases. Arthritis Rheum. 1998;41(9):200.

3. Lourie H. Spontaneous osteoporotic fracture of the sacrum. An unrecognized syndrome of the elderly. JAMA. 1982;248(6):715-7. doi: 10.1001/jama.248.6.715. [PubMed: 7097924].

4. Cooper KL, Beabout JW, McLeod RA. Supraacetabular insufficiency fractures. Radiology. 1985;157(1):15-7. doi: 10.1148/radiology.157.1.4034961. [PubMed: 4034961].

5. Gaucher A, Pere P, Bannwarth B. Insufficiency fractures of the pelvis. Clin Nucl Med. 1986;11(7):518. doi: 10.1097/00003072-19860700000016. [PubMed: 3731654 ].

6. Finiels H, Finiels PJ, Jacquot JM, Strubel D. Fractures of the sacrum caused by bone insufficiency. Meta-analysis of 508 cases. Presse Med. 1997;26(33):1568-73.

7. Alonso-Bartolome P, Martinez-Taboada VM, Blanco R, RodriguezValverde V. Insufficiency fractures of the tibia and fibula. Semin Arthritis Rheum. 1999;28(6):413-20. doi: 10.1016/S0049-0172(99)80007-9. [PubMed: 10406409].

8. Maugars Y, Dubois F, Berthelot JM, Dubois C, Prost A. Pain due to bone insufficiency as a symptom heralding femoral neck fracture. Rev Rhum Engl Ed. 1996;63(1):30-5. [PubMed: 9064107].

9. Jeffery CC. Spontaneous fractures of the femoral neck. Orthop Clin North Am. 1974;5(4):713-27. [PubMed: 4415867].

10. Kane RS, Burns EA, Goodwin JS. Minimal trauma fractures in older nursing home residents: the interaction of functional status, trauma, and site of fracture.JAm Geriatr Soc. 1995;43(2):156-9. doi:10.1111/j.1532- 5415.1995.tb06381.x. [PubMed: 7836640].

11. Johnell O, Kanis JA. An estimate of the worldwide prevalence and disability associated with osteoporotic fractures. Osteoporos Int. 2006;17(12):1726-33. doi: 10.1007/s00198-006-0172-4. [PubMed: 16983459].

12. Rodondi A, Chevalley T, Rizzoli R. Prevalence of vertebral fracture in oldest old nursing home residents. Osteoporos Int. 2012;23(11):2601-6 doi: 10.1007/s00198-012-1900-6. [PubMed: 22302103].

13. Benzinger P, Becker C, Kerse N, Bleibler F, Buchele G, Icks A, et al Pelvic fracture rates in community-living people with and without disability and in residents of nursing homes. J Am Med Dir Assoc. 2013;14(9):673-8. doi: 10.1016/j.jamda.2013.03.012. [PubMed: 23680402].

14. Martin-Hunyadi C, Heitz D, Kaltenbach G, Pfitzenmeyer P, Mourey F, Vogel T, et al. Spontaneous insufficiency fractures of long bones: a prospective epidemiological survey in nursing home subjects. Arch Gerontol Geriatr. 2000;31(3):207-14. doi:10.1016/S0167-4943(00)000819. [PubMed: 11154775].

15. Takamoto S, Masuyama T, Nakajima M, Seikiya K, Kosaka H, Morimoto $\mathrm{S}$, et al. Alterations of bone mineral density of the femurs in hemiplegia. Calcif Tissue Int. 1995;56(4):259-62. doi: 10.1007/BF00318043. [PubMed: 7767834].

16. Kane RS, Goodwin JS. Spontaneous fractures of the long bones in nursing home patients. Am J Med. 1991;90(2):263-6. doi: 10.1016/00029343(91)90553-A. [PubMed: 1899968].

17. Wong TC, Wu WC, Cheng HS, Cheng YC, Yam SK. Spontaneous fractures in nursing home residents. Hong Kong Med J. 2007;13(6):427-9. [PubMed: 18057429]. 